\title{
Relaxation versus exercise for improved quality of life in lymphoma survivors - a randomised controlled trial
}

\author{
Suchita Hathiramani ${ }^{1}$ (D) R. Pettengell ${ }^{2} \cdot$ H. Moir ${ }^{3} \cdot$ A. Younis $^{1}$ \\ Received: 11 June 2020 / Accepted: 17 September 2020 / Published online: 28 September 2020 \\ (C) The Author(s) 2020
}

\begin{abstract}
Purpose Lymphoma survivors experience persisting needs as a consequence of disease and treatment, which have an impact on quality of life (QoL). There is evidence supporting the use of relaxation and exercise to improve QoL, but there is no agreement on which is more beneficial. This study aims to compare a relaxation intervention versus an exercise intervention to determine which has a greater impact on QoL post-chemotherapy.

Methods Eligible participants $(n=46)$ were randomised to a relaxation or exercise intervention for 12 weeks. QoL was assessed at baseline, 6 weeks and post-intervention using the European Organisation for Research and Treatment of Cancer QoL Questionnaire Core 30 (EORTC QLQ-C30) questionnaire, which is a valid and reliable tool. The summary score and all EORTC domains were assessed.

Results There was a significant difference in QoL post-intervention between groups $(p=0.029)$ while adjusting for baseline QoL, with the exercise group demonstrating a larger improvement. Within-group QoL significantly improved pre- to postintervention in both the relaxation $(p=0.036)$ and exercise $(p=0.004)$ groups.

Conclusions A self-management intervention of either exercise or relaxation can help significantly improve QoL in lymphoma survivors following chemotherapy. While exercise is preferred, a relaxation intervention would also have a beneficial impact on QoL.

Implications for Cancer Survivors Lymphoma survivors should be routinely screened and those with decreased QoL referred for an exercise programme, or relaxation for survivors who are unable to exercise or choose not to. A home-based programme can have a significant positive impact on QoL and is a feasible and effective method in the current climate.
\end{abstract}

Trial registration number Clinical Trials ID NCT02272751

Keywords Lymphoma survivors · Exercise · Relaxation · Self-management · Quality of life

\section{Introduction}

It is well recognised that a large number of haematological cancer survivors continue to experience physical and psychological unmet needs following treatment, resulting in a decreased quality of life (QoL) [1-3]. It is also recognised that the immediate period following treatment is a particularly difficult time, when survivors may feel isolated and abandoned

Suchita Hathiramani

k1065642@hscs.sgul.ac.uk

1 Kingston University and St. George's University of London, Cranmer Terrace, London SW17 0RE, UK

2 St. George's Healthcare NHS Trust, London, UK

3 Kingston University London, Kingston Upon Thames, UK
[4-6]. Several studies [7-10] have been carried out to assess the effectiveness of various rehabilitation interventions on QoL in cancer survivors. Some studies support the use of exercise such as aerobic and/or resistance training [7, 8], while others recommend the use of relaxation techniques including mindfulness-based stress reduction, progressive muscle relaxation and guided imagery $[9,10]$. Both interventions appear to have a positive effect on QoL, but there is no consensus on which is more effective, and no standardised pathways following chemotherapy, despite the fact that cancer survivors report a need for further support during this transition phase [11]. In the majority of these studies, the relaxation or exercise interventions have been compared with a control group, and there has been a call for future studies to rule out potential placebo effects and compare with active control or other empirically supported interventions $[12,13]$, for instance relaxation to exercise. 
Studies on cancer survivors have been carried out in various settings, including both group-based supervised programmes and self-management. Recent systematic reviews and meta-analyses of RCTs of exercise for cancer patients and survivors have reported significant beneficial effects for supervised exercise interventions on QoL and a lesser effect for unsupervised $[14,15]$. This could be due to greater direction and motivation from a trainer and access to equipment. However, Swartz et al. [16] highlight that while there is evidence that exercise can improve the QoL of cancer survivors, few interventions have been translated into practice. This could be due to trial designs with high resources and clinical settings, and these authors suggest that home-based interventions may be a way of enabling the translation from research to practice [16]. Similarly, despite evidence of the efficacy of relaxation programmes for cancer survivors, the training and resources required to provide professionally administered psychosocial interventions can be a major barrier to their routine use [17]. Hence, although home-based programmes appear to have lower efficacy than supervised programmes, their greater accessibility, wider reach and potential long-term sustainability may make a self-managed approach also beneficial to survivors.

Furthermore, there is a drive towards self-management for cancer survivors, with the National Cancer Survivorship Initiative (NCSI) in the United Kingdom (UK) calling for a need to increase service user involvement and selfmanagement [4]. Self-management can empower cancer patients and survivors, increase their confidence to manage problems associated with the disease and its treatment and enhance the quality of life [4, 18]. Survivors themselves have reported a preference for home-based self-management over group classes in a clinical setting [19-21]. In addition, due to the present COVID-19 pandemic, efforts are being made to reduce the exposure of cancer survivors to the virus [22]. Hence, effective, evidence-based self-management interventions are more pertinent now. The majority of survivorship studies have been carried out on the most prevalent cancers such as breast and prostate cancer $[9,10,23]$, and there is a lack of studies on other cancer groups [1,23] including haematological cancers such as lymphoma.

The Relaxation and Exercise In Lymphoma survivors (REIL) study was carried out to address some of these issues [24]. The REIL study aims to compare the effect of two homebased interventions on QoL in a group of lymphoma survivors within 6 weeks post-chemotherapy to determine which intervention - relaxation or exercise - results in a larger impact on QoL. The REIL study is the first randomised controlled trial (RCT) comparing home-based relaxation with a home-based exercise programme in lymphoma survivors following chemotherapy. Results will contribute to a better understanding of the efficacy of these interventions and build towards the implementation of evidence-based programmes to improve QoL in lymphoma survivors. This paper presents findings from the primary outcome measure, the European Organisation for Research and Treatment of Cancer Quality of Life Questionnaire Core 30 (EORTC QLQ-C30, version 3.0) $[25,26]$. Secondary results will be reported elsewhere.

\section{Aim}

To compare the effect of two home-based interventions (relaxation and exercise) on QoL in a sample of lymphoma survivors post-chemotherapy.

\section{Methods}

\section{Study design}

The REIL study is a randomised clinical intervention trial. Participants who consented were randomised to a relaxation or an exercise intervention. Outcome measures were assessed at baseline prior to intervention, at 6 weeks, and on completion of the 12-week intervention.

\section{Ethical approval}

The study received ethical approval from Camden and Islington National Research Ethics Service (13/LO/1327), and from St. George's Hospital Joint Research and Enterprise Office (JREO) (13.0108) where the research was carried out. The study is registered on a publicly accessible database, ClinicalTrials.gov, NCT02272751.

\section{Participants}

Eligible participants included patients with histologically confirmed lymphoma in remission post-chemotherapy, chemotherapy treatment completed within the last 6 weeks, age 18 years or older, able to give informed consent, good performance status (assessed by the Eastern Cooperative Oncology Group [ECOG] status 0-2) [27] and medically able to undertake exercise. The following were exclusion criteria-patients with active disease, unstable angina or unexplained electrocardiogram, poor performance status (ECOG status 3 or more), pregnancy, difficulty breathing at rest, persistent cough, fever or illness, or any cognitive impairment limiting the ability to give informed consent or complete QoL questionnaires. Informed consent was obtained from all participants, and participants were informed that they could withdraw at any time. At baseline, patient demographics including gender, age, social history and medical history were recorded. 


\section{Study settings}

Participants were recruited from a single National Health Service (NHS) setting - the Haematology-Oncology OutPatient (HOOP) Clinic at St George's Hospital, London. Assessment for eligibility, recruitment, medical screening and obtaining informed consent was carried out by the patients' medical consultant (RP). Assessment of outcome measures and delivery of interventions were carried out by the principal investigator $(\mathrm{SH})$ following participants' scheduled follow-up appointments.

\section{Interventions-relaxation and exercise}

The relaxation intervention comprised an audio CD incorporating relaxation techniques including mindfulness meditation, deep breathing exercises, guided visualisation and progressive muscular relaxation. The exercise intervention comprised a programme of aerobic, upper and lower limb resistance exercise, core stability and stretches to be performed independently at home. Both interventions are described in detail in the REIL study protocol [24]. This protocol was adhered to throughout the study. Both interventions were similar in aspects including location (home), frequency and duration (50 min three times a week for 12 weeks). Participants in both groups also had equal contact with the researcher, approximately $3 \mathrm{~h}(1 \mathrm{~h}$ for each assessment and education session), and were able to call researcher for advice whenever needed. Both groups were provided with written information and resources including audio and visual aids to enable selfmanagement. Participants in both groups were advised to continue to resume their normal activity as able, with their intervention as a supplement to normal habit [24].

\section{Outcome measures}

The primary outcome measure is QoL, assessed by the EORTC QLQ-C30 summary score. The QLQ-C30 is a multidimensional health-related QoL questionnaire. This selfreported questionnaire is recognised as a valid and reliable tool and is the most widely used outcome measure used to assess QoL in cancer survivorship research [28]. Although the QLQ-C30 provides a wealth of information about QoL, a challenge is the multiple outcomes it generates. As a result, the EORTC group introduced and tested a single summary score of the QLQ-C30 questionnaire [29]. In addition to reducing the risk to type I errors, the use of the summary score can also ensure direct comparability between studies [29]. The EORTC group now recommends the use of the summary score and this was the primary outcome measure for the REIL study. The summary score and other EORTC domains were assessed at all three time points.

\section{Sample size}

Sample size was calculated to determine clinically relevant effects on the primary outcome measure. A minimally important difference of 10 points in the EORTC QLQ-C30 score is generally accepted as clinically meaningful [30], and calculations were based on comparison of means between two groups. It was determined that a minimum 46 participants was required to detect a significant change in the EORTC summary score. This calculation assumed a two-sided significance level $(\alpha)$ of 0.05 , power of $80 \%(\beta=0.20)$, a standard deviation from EORTC website reference values and a dropout rate of $34 \%$ as reported in similar studies [31]. Based on this, a minimum of 23 participants was required in each group.

\section{Randomisation}

Participants were assigned to either the relaxation or exercise group using a computer-generated random allocation list. This was prepared independently by a biostatistician otherwise uninvolved in the study using randomisation software and saved on a secure database that could not be modified by the researchers. Each participant was assigned an anonymous ID number on enrolment, and each number allocated the intervention on the list.

All assessments were carried out by the principal investigator $(\mathrm{SH})$; hence, it was not possible to blind the investigator to intervention. Participants also could not be blinded due to the nature of the intervention.

\section{Data analysis}

Data was entered into the Microsoft Excel (2013) database by SH and analysed with support from the other researchers and a statistician independent of the study using IBM SPSS version 22 (SPSS, Inc., Chicago, IL) statistical software package. Summary scores plus scores from all other questionnaire domains were calculated as recommended by the EORTC scoring manual, missing data handled as recommended by scoring guidelines. Data was first assessed to check distribution using a combination of visual inspection, assessment of skewness and kurtosis and formal normality tests (Shapiro-Wilk). All data followed a normal distribution. Significance testing of baseline differences in a randomised sample is discouraged by CONSORT guidelines [32] and this was not performed; descriptive statistics are used to describe baseline characteristics of both groups. Analysis of covariance (ANCOVA) was used to compare differences in the QoL at 12 weeks using baseline QoL as a covariate. Post hoc paired-sample $t$ tests for comparison pre-post intervention was tested within groups with the Bonferroni corrections. 


\section{Results}

\section{Participants}

Participants were recruited from September 2014 to December 2016. Sixty-two potential participants were approached. Of these, 46 (29 female and 17 male) consented and were enrolled in the study, 23 randomised to each intervention. Participant demographics are summarised in Table 1.

Five participants failed to complete the study $(n=3$ relaxation, $n=2$ exercise), reasons included no time $(n=3)$, not interested $(n=1)$ and disease progression $(n=1)$. This demonstrated a dropout rate of $13 \%$ for the relaxation group and $9 \%$ for the exercise group. Little's MCAR test indicated that data were missing completely at random, and pairwise deletion for complete case analysis was applicable for this dataset. The CONSORT flow diagram of the study is presented in Fig. 1. No adverse events or injuries were reported in either group.

\section{Between-group effect-QLQ-C30 summary score}

There was a significant difference in QoL between the two groups at 12 weeks $(F(1,35)=5.208, p=0.029 ; 95 \% \mathrm{CI}$ $0.608-10.413)$ while adjusting for baseline. The effect size observed was large (partial eta squared $=0.130$ ). The mean adjusted QoL summary score at 12 weeks was 91.07 (95\% CI 86.69-93.58) for the exercise group and 83.68 (95\% CI 81.18-88.07) for the relaxation group, indicating a beneficial effect of exercise vs. relaxation. Mean values of the summary score at 12 weeks and all EORTC domains are summarised in Table 2.

Table 1 Baseline demographics

\begin{tabular}{|c|c|c|c|}
\hline & Total sample, $n=46$ & Relaxation, $n=23$ & Exercise, $n=23$ \\
\hline Age, years $($ mean $\pm S D)$ & $61( \pm 16.7)$ & $60.4( \pm 19.4)$ & $61.5( \pm 13.9)$ \\
\hline \multicolumn{4}{|l|}{ Gender $(n, \%)$} \\
\hline Male & $17(37)$ & $7(30.4)$ & $10(43.5)$ \\
\hline Female & $29(63)$ & $16(69.6)$ & $13(56.5)$ \\
\hline \multicolumn{4}{|l|}{ Marital status $(n, \%)$} \\
\hline Married/partner & $31(67)$ & $14(61)$ & $17(74)$ \\
\hline Single & $10(22)$ & $4(17)$ & $6(26)$ \\
\hline Widowed & $5(11)$ & $5(22)$ & $0(0)$ \\
\hline \multicolumn{4}{|l|}{ Ethnicity $(n, \%)$} \\
\hline Caucasian & $38(83)$ & $18(78.3)$ & $20(87.1)$ \\
\hline Asian & $4(9)$ & $3(13)$ & $1(4.3)$ \\
\hline Afro-Caribbean & $3(6)$ & $2(8.7)$ & $1(4.3)$ \\
\hline Other & $1(2)$ & $0(0)$ & $1(4.3)$ \\
\hline \multicolumn{4}{|l|}{ Comorbidities $(n, \%)$} \\
\hline None & $14(30.4)$ & $6(26.1)$ & $8(34.8)$ \\
\hline 1 & $16(34.8)$ & $5(21.7)$ & $11(47.8)$ \\
\hline 2 & $10(21.7)$ & $6(26.1)$ & $4(17.4)$ \\
\hline 3 or more & $6(13.1)$ & $6(26.1)$ & $0(0)$ \\
\hline \multicolumn{4}{|l|}{ ECOG status $(n, \%)$} \\
\hline 0 & $7(15)$ & $4(17.4)$ & $3(13)$ \\
\hline 1 & $18(39)$ & $7(30.4)$ & $11(48)$ \\
\hline 2 & $21(46)$ & $12(52.2)$ & $9(39)$ \\
\hline \multicolumn{4}{|l|}{ Employment $(n, \%)$} \\
\hline Retired & $21(45.7)$ & $11(47.8)$ & $10(43.6)$ \\
\hline Sick leave & $9(19.6)$ & $4(17.5)$ & $5(21.6)$ \\
\hline Fulltime work & $7(15.3)$ & $3(13)$ & $4(17.5)$ \\
\hline Homemaker & $4(8.6)$ & $3(13)$ & $1(4.3)$ \\
\hline Part-time work & $2(4.3)$ & $0(0)$ & $2(8.7)$ \\
\hline Unemployed & $1(2.2)$ & $0(0)$ & $1(4.3)$ \\
\hline Other & $2(4.3)$ & $2(8.7)$ & $0(0)$ \\
\hline
\end{tabular}


Fig. 1 Participant flow

Table 2 EORTC QLQ-C30 domains - means $( \pm \mathrm{SD})$ of both groups and between-group comparison, adjusted for baseline.

*Indicates significant difference between groups

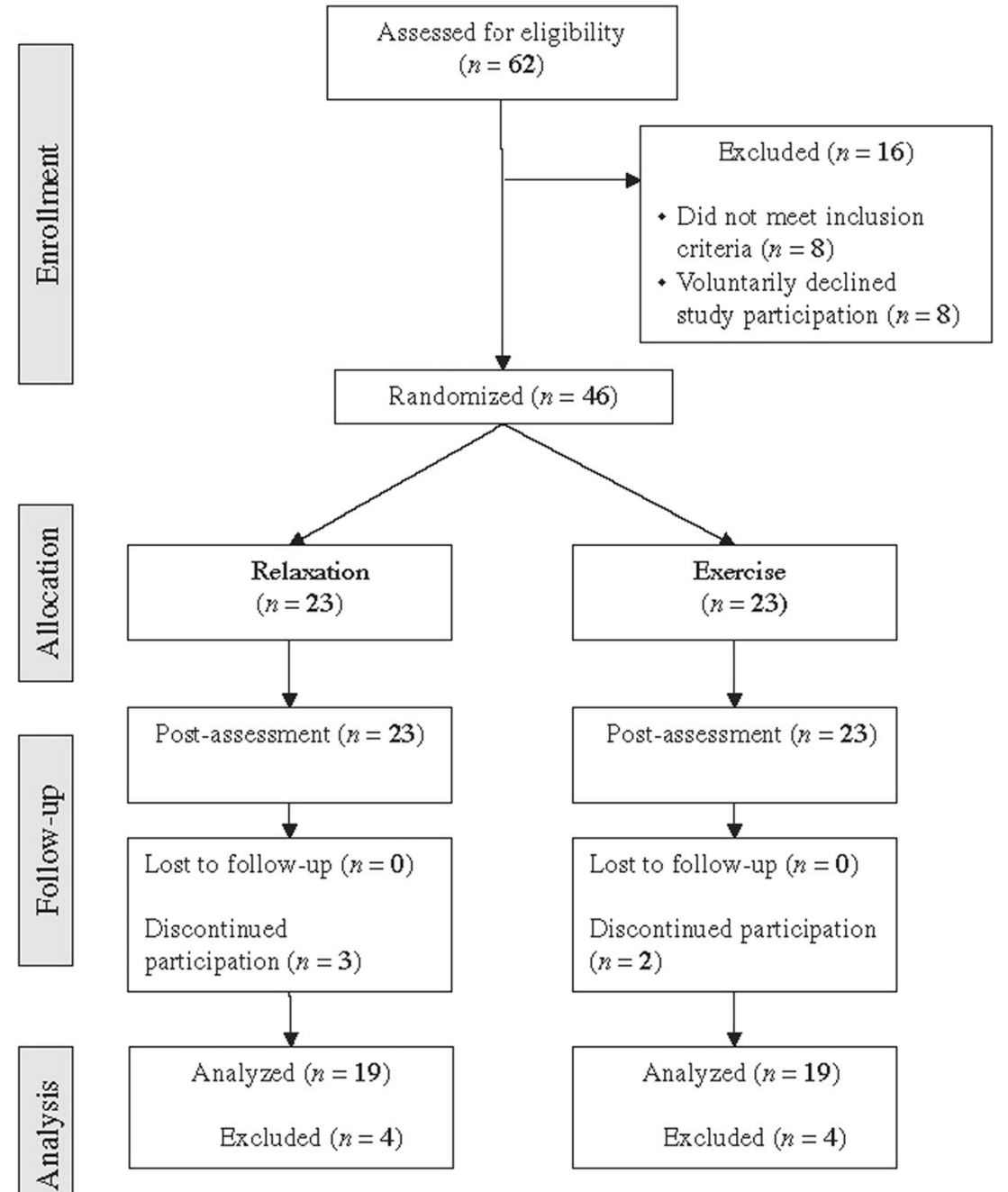

\begin{tabular}{llll}
\hline & Mean 12 -week relaxation & Mean 12-week exercise & $p=$ \\
\hline Summary score & $83.69 \pm 11.34$ & $91.07 \pm 7.03$ & $0.029^{*}$ \\
Physical function & $77.54 \pm 18.02$ & $89.21 \pm 11.03$ & $0.038^{*}$ \\
Role function & $81.58 \pm 24.15$ & $87.72 \pm 14.53$ & 0.441 \\
Emotional function & $82.02 \pm 20.65$ & $88.60 \pm 15.01$ & 0.267 \\
Cognitive function & $78.07 \pm 16.71$ & $86.84 \pm 17.19$ & 0.367 \\
Social function & $87.72 \pm 17.43$ & $92.10 \pm 17.01$ & 0.444 \\
Fatigue & $35.67 \pm 22.40$ & $17.54 \pm 18.63$ & $0.009 *$ \\
Nausea/vomiting & $4.39 \pm 7.54$ & $0.88 \pm 3.82$ & 0.080 \\
Pain & $14.04 \pm 14.97$ & $5.26 \pm 9.71$ & $0.017 *$ \\
Dyspnoea & $19.30 \pm 23.08$ & $10.56 \pm 15.92$ & 0.093 \\
Insomnia & $17.54 \pm 23.22$ & $5.26 \pm 12.49$ & 0.155 \\
Appetite loss & $10.53 \pm 19.41$ & $8.77 \pm 15.08$ & 0.588 \\
Constipation & $10.53 \pm 19.41$ & $8.77 \pm 15.08$ & 0.588 \\
Diarrhoea & $7.02 \pm 17.84$ & $3.51 \pm 10.51$ & 0.342 \\
Financial problems & $8.77 \pm 24.45$ & $7.41 \pm 18.28$ & 0.911 \\
Global QoL & $74.12 \pm 15.93$ & $80.70 \pm 15.48$ & 0.374 \\
\hline
\end{tabular}




\section{Other QLQ-C30 domains}

There was a significant difference between the two groups for physical function $(\mathrm{PF})(F(1,35)=4.642, p=0.038 ; 95 \% \mathrm{CI}$ $0.465-15.662)$, fatigue $(F(1,35)=7.763, p=0.009,95 \% \mathrm{CI}$ 4.339-27.640) and pain $(\mathrm{F}(1,35)=6.268, p=0.017,95 \% \mathrm{CI}$ 1.610-15.418) subscales, adjusting for baseline values.

There were no significant differences between groups for other subscales.

\section{Improvement over time}

Within-group analyses demonstrated a significant difference in pre-post QoL summary score in both groups - mean difference pre-post in the relaxation group was $6.198( \pm 11.92), p=$ $0.036,95 \%$ CI $0.453-11.943$; and in the exercise group, the mean difference was $8.839( \pm 11.563), p=0.004,95 \%$ CI 3.266-14.413. Within-group improvement in QoL from baseline to 12 weeks is demonstrated in Fig. 2.

\section{Discussion}

The aim of this study was to compare the effect of two homebased interventions on QoL in a sample of lymphoma survivors within 6 weeks post-chemotherapy. Results indicate a significant difference between the groups following intervention, with the exercise group demonstrating a larger improvement in overall QoL than the relaxation group. A significant difference between groups in $\mathrm{PF}$, fatigue and pain symptom scales was also observed, once again with the exercise group demonstrating a larger improvement in these domains.

Similar to this study, other studies on exercise in cancer survivors have similarly demonstrated a positive effect on QoL and other outcomes closely related to QoL such as PF, fatigue and pain $[7,14,15,33,34]$. Exercise has been shown to have a significant positive effect on physical factors including body weight, body mass index, muscle strength, aerobic fitness, fatigue and functional ability in cancer survivors, as well as psychological factors including distress, anxiety and depression [13, 32, 35, 36]. Hence, several national and international cancer organisations recommend exercise for cancer survivors [37-40].

Following these findings, it can be argued that a homebased exercise programme post-chemotherapy is more effective at improving QoL than a relaxation programme. It must be highlighted however that while the exercise group demonstrated a larger improvement, the relaxation group also demonstrated a significant difference in QoL following intervention. Other studies have also reported improvements in QoL following a relaxation programme $[9,41]$. While the mechanism and physiology of relaxation are different from undertaking exercise, relaxation techniques have also shown to have a positive effect on physical and psychological symptoms in cancer survivors including pain, fatigue, quality of life, anxiety and depression $[9,41-43]$. The use of complementary and alternative medicine (CAM) including relaxation techniques is growing in popularity, and it is reported that cancer survivors are more likely to use CAM than the general population [44]. Up to $89 \%$ of survivors report the use of CAM including mind-body approaches such as relaxation $[45,46]$, choosing to do so without being advised by a healthcare professional. Hence, a proportion of cancer and lymphoma survivors may have a preference for relaxation programmes. Hence, as the results of this study also indicate, the benefits of relaxation should not be overlooked, and both these interventions are beneficial to cancer survivors - relaxation could be considered an effective alternative intervention to offer to survivors who chose to or who are unable to exercise.

While studies have shown the effectiveness of mindfulness-based stress reduction (MBSR) on QoL, the traditional MBSR course requires a considerable time
Fig. 2 Mean QOL over time at baseline, 6 weeks and 12 weeks (dark grey line represents exercise intervention; light grey line represents relaxation intervention)

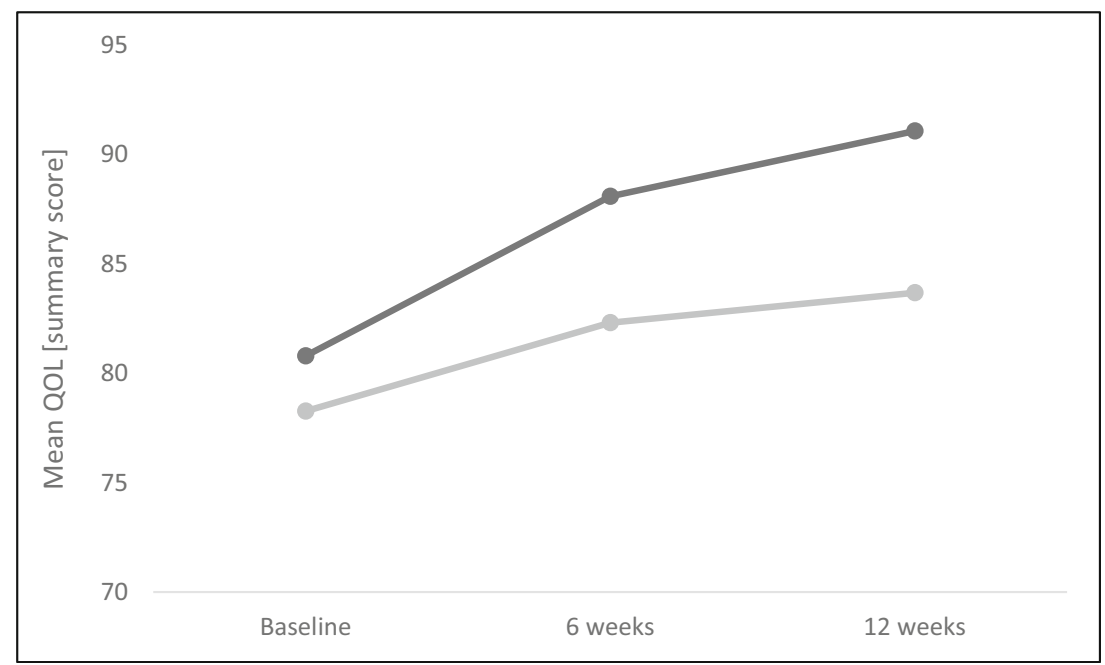


commitment and this could be a reason for non-adherence or even non-participation [47]. The authors have acknowledged there is scope to tailor the intervention so that it is less intensive, for instance, less time-consuming for the participant [47]. The relaxation intervention used in the REIL study meets criteria described for low-intensity interventionsadministered in non-face-to-face setting, delivered by a nonmental health practitioner (delivered by a physiotherapist specialising in oncology), be more accessible (programme available in their NHS follow-up clinic) and be briefer for the practitioner compared to therapist delivered treatments [48]. Hence, this home-based relaxation programme is a feasible and realistic intervention for improving the QoL of lymphoma survivors unable to exercise.

It is recognised that cancer survivors suffering from comorbid conditions such as heart disease, hypertension, asthma/ COPD, diabetes and osteoarthritis experience lower levels of QoL [49]. While exercise has a beneficial impact on a variety of these comorbid conditions, these survivors may require close monitoring and exercise under supervision. For this group, a self-managed home relaxation programme may help to improve their QoL, if they are unable to perform unsupervised exercise to do so, or experience any contraindications. Other groups of survivors may have a preference towards relaxation for a variety of other reasons including previous history of complementary and alternative medicine (CAM) use, or dislike of exercise. This group may also benefit from a self-managed relaxation programme if experiencing ongoing symptoms leading to decreased QoL.

Lymphoma survivors experience a heterogeneity of unmet needs [50] — while some complain of no needs following chemotherapy, others experience symptoms ranging from physical (e.g. fatigue, pain, nausea) and/or psychological (e.g. anxiety, depression, insomnia). This wide range of baseline needs complicate the provision of adequate support, and a flexible approach is required with opportunity to access different types of support at different times post-treatment [6], based on individual need and preference. It is widely recommended that interventions are tailored for individual patients and that patient choice should be a key feature in survivorship care [4]. As both the relaxation and exercise interventions improved QoL, offering a choice to patients who experience decreased QoL could be a way towards the flexible, tailored approach recommended for survivorship care. The main focus should be the assessment of survivors and identifying those in need of support to improve QoL.

As not all cancer survivors experience unmet needs and decreased QoL, some cancer survivors may not feel the need to undertake self-management practices as they feel they already have a good QoL [51]. This was seen in the REIL study, where some participants reported no unmet needs following chemotherapy and found no benefit from a home-based intervention [11]. The sample of lymphoma survivors in this study was already fairly active, as participants had to have an ECOG performance status of $0-2$ [27] which ranged from fully active without restriction to mobile and capable of all self-care but unable to carry out work activities in order to be included in the study. Patients who were capable of limited self-care or confined to a bed or chair more than $50 \%$ of waking hours were excluded from the study; hence, the results could be affected by potential ceiling effects in the patient-reported outcome measure, where baseline QoL was a good score (higher score for summary score and function scales, and lower score for symptom scales) and thus less sensitive to change. More importantly, those with severe comorbidities resulting in a greater decrease in QoL and possibly in greater need of intervention (either relaxation or exercise) and support may have been excluded from this study if they did not meet performance status criteria or were unable to exercise independently. Hence, it is important to assess which survivors are most likely to benefit from an intervention programme, whether relaxation or exercise, and target those with the highest needs [52]. Screening for factors that negatively impact QoL such as comorbidity, moderate to severe symptom burden, psychological distress and fatigue should alert health professionals to a potential need for support and allow earlier intervention to improve QoL in those most affected [3, 53, 54].

As both the relaxation and exercise programmes demonstrated significant improvement in QoL post-intervention, another approach may be to integrate elements of both into one programme. Lee et al. [55] also compared two interventions in cancer survivors, one focusing on physical training (qigong) and one on mental (stress management), to a control group. These authors also found both groups demonstrated significant improvement in physical and psychological functions at 12 weeks compared with a control group, and also recommend that cancer survivors receive both physical and mental support as they can benefit from both. Multimodal interventions including both physical and psychological aspects have also been recommended by others [17, 19, 56]. Further study on the development of a multidimensional home-based intervention including aspects of both relaxation and exercise in a larger sample of lymphoma survivors is recommended in the future.

Lee et al. [55] report that although educational resources including DVDs and CDs were provided to encourage home practice, lack of persistence can result from lack of supervision and peer encouragement, and they recommend continuous and periodic involvement by professional coaches at a minimum of once a week. A qualitative study to explore gynaecological cancer survivors' experience of a homebased exercise intervention also found that weekly telephone contact was favourable as it seemed to create an accountability to exercise, linked with a rapport with the contacting therapist [19]. In contrast, it has been stated that self-management in 
cancer survivorship should encompass understanding how and when to seek support, making lifestyle changes to promote health and wellbeing, and the onus should be on individuals to initiate contact with healthcare professionals [4]. This latter approach was adopted for the REIL study, using supported self-management during the transition phase. Here, while both the relaxation and exercise interventions were selfmanaged, participants were educated and advised to contact the researcher (healthcare professional with expertise in cancer rehabilitation) any time additional support or advice was required. In spite of evidence for the greater effectiveness of supervised programmes, cancer survivors report a preference for home-based and unsupervised exercise interventions for a variety of reasons for instance to avoid travel, time commitments, issues around cost, intimidation, and to avoid going back to hospital [20, 21, 57]. Interventions tailored to individual need and preference are essential for maximising recruitment and adherence and enhancing outcomes [21]. Homebased interventions can also include motivational support and guidance using distance-based approaches.

In the current climate of social distancing, distance-based interventions may represent a more practical and accepted method of support and rehabilitation for lymphoma survivors. While several studies on self-management and distance-based initiatives for cancer survivors including telephone counselling [58], mobile applications [59] and internet [60] have demonstrated significant positive effects including reduced physical side effects from treatment, reduced anxiety and depression, improved health behaviour and increased QoL, these interventions have faced barriers to implementation. Such barriers include not allocating resources to 'new' initiatives, unfamiliarity with the internet, reduced access to a smartphone and patient or healthcare professional attitudes (e.g. preferring face-to-face consultation or reservations about new technology) [22]. However distance-based strategies are now being promoted in most populations, in particular those at risk of serious complications from coronavirus, such as cancer survivors. Key organisations in the UK including the NHS England [61] and the Chartered Society of Physiotherapy (CSP) [62] now recommend distance-based assessment and rehabilitation as the primary strategy for cancer survivors where possible. Based on a high trial adherence, the absence of adverse events and positive satisfaction with the programmes [11], the home-based interventions in this study are considered feasible for lymphoma survivors in the transition phase. These interventions require comparatively low resources and personnel, incorporate the recommended elements of self-management, use of patient-reported outcome measures and tailored support when required, and have demonstrated a significant improvement in QoL; hence, such interventions would continue to be effective and practical even on the resumption of standard healthcare.
Strengths of the REIL study include testing of two theorybased interventions, use of patient-reported outcome measures and low dropout rates (17\%). To our knowledge, this is the first RCT directly comparing the efficacy of two interventions on QoL; previous studies have used a comparison group as an active control group [63]. While it was not an aim of this study to directly evaluate the feasibility of the interventions, participants who completed their interventions in both groups reported at the end of the study questionnaire that they were able to fit this into their daily life [11]. Limitations include the small sample size. Difficulties were encountered with recruitment of eligible participants including relapse or disease progression, impact of lymphoma and its treatment, scheduling difficulties and technical problems. Similar problems have been reported in other studies in cancer survivors [64]. While this study did not include measures to assess and encourage participant adherence such as daily or weekly telephone calls or wearable activity trackers, the intervention programmes were designed to be carried out in 'realworld' settings and hence may be a more realistic representation of what lymphoma survivors are able to undertake. Also, no measures were taken to limit the practice of any other interventions in each group. Hence, participants in the relaxation group could have also taken up exercise on their own without being advised to, and vice-versa; this potential contamination could have biased results. However, once again, the addition of an intervention as a supplement to normal life without limiting other activities is a more realistic representation of real-world conditions. The potential ceiling effect of the EORTC QLQ-C30 questionnaire as discussed and the inability to stratify the sample due to small sample size for instance by physical activity are other study limitations. Another limitation is the predominance of female patients in the study sample. This gender imbalance has been reported in previous studies on interventions in cancer survivors - the authors have reported a clear majority of female participants from 73 to $87 \%$ [56]. This is in keeping with evidence that participation in population-based research is generally higher among women than among men [65]. Further research is needed to give insight into this gender difference, and there is a need for the development and testing of interventions with greater appeal to male cancer survivors $[18,65]$. The principal investigator conducting both interventions also collected the data, which may have led to bias. Self-selection of participants may have resulted in a sample of lymphoma survivors who were motivated to undertake a self-management intervention, but this limitation is inherent in such studies.

\section{Conclusions}

Lymphoma survivors may experience decreased QoL following chemotherapy and would benefit from assessment and referral for ongoing support and intervention as required. Based on this study's findings, a home-based exercise programme 
results in a greater improvement in QoL than a relaxation programme. However, a relaxation programme would also have a similar effect, albeit to a lesser extent. Referral to either programme based on individual need and/or preference would aid in improvement QoL post-chemotherapy. Both interventions are an effective, feasible, less costly and more practical alternative to supervised group interventions in lymphoma survivors, particularly in the current climate of the COVID-19 pandemic and shielding of potentially vulnerable individuals.

\section{Implications for Cancer survivors}

Self-management programmes with support as required are recommended for lymphoma survivors who demonstrate decreased QoL post-chemotherapy. A home-based exercise programme appears more effective than a relaxation programme in improving QoL and may be the favoured approach. However, for patients who are unable to exercise or choose not to, a home-based relaxation programme would also significantly improve QoL. Multidimensional programmes combining aspects of both may also be a way forward.

Acknowledgements The authors thank all the participants who volunteered for this study and staff at the HOOP clinic St. George's Hospital, all of whom made this research possible. Thanks also to the Chartered Society of Physiotherapy, UK for the Academically Accredited Courses Award awarded to the corresponding author.

Funding This study received no funding; the research is towards the corresponding author's $\mathrm{PhD}$.

\section{Compliance with ethical standards}

Conflict of interest The authors declare that they have no conflict of interest.

Ethical approval All procedures performed in studies involving human participants were in accordance with the ethical standards of the institutional and national research committee and with the 1964 Helsinki declaration and its later amendments or comparable ethical standards.

Informed consent Informed consent was obtained from all participants included in the study.

Open Access This article is licensed under a Creative Commons Attribution 4.0 International License, which permits use, sharing, adaptation, distribution and reproduction in any medium or format, as long as you give appropriate credit to the original author(s) and the source, provide a link to the Creative Commons licence, and indicate if changes were made. The images or other third party material in this article are included in the article's Creative Commons licence, unless indicated otherwise in a credit line to the material. If material is not included in the article's Creative Commons licence and your intended use is not permitted by statutory regulation or exceeds the permitted use, you will need to obtain permission directly from the copyright holder. To view a copy of this licence, visit http://creativecommons.org/licenses/by/4.0/.

\section{References}

1. Damlaj M, El Fakih R, Hashmi SK. Evolution of survivorship in lymphoma, myeloma and leukemia: metamorphosis of the field into long term follow-up care. Blood Rev. 2019;33:63-73.

2. Ciavarella S, Minoia C, Quinto AM, Oliva S, Carbonara S, Cormio $\mathrm{C}$, et al. Improving provision of care for long-term survivors of lymphoma. Clin Lymphoma Myeloma Leuk. 2017;17(12):e1-9.

3. Wu HS, Harden JK. Symptom burden and quality of life in survivorship: a review of the literature. Cancer Nurs. 2015;38(1):E29-54.

4. National Cancer Survivorship Initiative (NCSI). Living with and beyond cancer: taking action to improve outcomes. 2013. https:// assets.publishing.service.gov.uk/government/uploads/system/ uploads/attachment_data/file/181054/9333-TSO-2900664-NCSI Report FINAL.pdf Accessed 11 Aug 2020.

5. Hackett F, Dowling M. Lymphoma survivors' experiences at the end of treatment. J Clin Nurs. 2019;28:400-9.

6. Monterosso L, Taylor K, Platt V, Lobb E, Krishnasamy M, Musiello T, et al. A qualitative study of the post-treatment experiences and support needs of survivors of lymphoma. Eur J Oncol Nurs. 2017;28:62-8.

7. Gerritsen JK, Vincent AJ. Exercise improves quality of life in patients with cancer: a systematic review and meta-analysis of randomised controlled trials. Br J Sports Med. 2016;50(13):796803.

8. Mishra SI, Scherer RW, Geigle PM, et al. Exercise interventions on health-related quality of life for cancer survivors. Cochrane Database Syst Rev. 2012;8:CD007566.

9. Lengacher CA, Reich RR, Paterson CL, Ramesar S, Park JY, Alinat $\mathrm{C}$, et al. Examination of brad symptom improvement resulting from mindfulness-based stress reduction in breast cancer survivors: a randomized clinical trial. J Clin Oncol. 2016;34(24):2827-34.

10. Charalambous A, Giannakopoulou M, Bozas E, Paikousis L. A randomized controlled trial for the effectiveness of progressive muscle relaxation and guided imagery as anxiety reducing interventions in breast and prostate cancer patients undergoing chemotherapy. Evid Based Complement Alternat Med. 2015;270876:1-10. https://doi.org/10.1155/2015/270876.

11. Hathiramani S, Pettengel R, Moir H, Younis A. Lymphoma survivors' experience of participation in a home-based intervention postchemotherapy. Qual Life Res. 2019;28:2951-5.

12. Bower JE. Mindfulness interventions for cancer survivors: moving beyond wait-list control groups. J Clin Oncol. 2016;34:3366-8.

13. Buchanan DR, White JD, O'Mara AM, et al. Research-design issues in cancer-symptom-management trials using complementary and alternative medicine: lessons from the National Cancer Institute Community clinical oncology program experience. J Clin Oncol. 2005;23:6682-9.

14. Sweegers MG, Altenburg TM, Chinapaw MJ, Kalter J, Verdonckde Leeuw IM, Courneya KS, et al. Which exercise prescriptions improve quality of life and physical function in patients with cancer during and following treatment? A systematic review and metaanalysis of randomised controlled trials. Br J Sports Med. 2018;52:505-13.

15. Buffart LM, Kalter J, Sweegers MG, Courneya KS, Newton RU, Aaronson NK, et al. Effects and moderators of exercise on quality of life and physical function in patients with cancer: an individual patient data meta-analysis of 34 RCTs. Cancer Treat Rev. 2017;52: 91-104.

16. Swartz MC, Lewis ZH, Lyons EJ, Jennings K, Middleton A, Deer $\mathrm{RR}$, et al. Effect of home and community-based physical activity interventions on physical function among cancer survivors: a systematic review and meta-analysis. Arch Phys Med Rehabil. 2017;98(8):1652-65. 
17. Jacobsen PB, Phillips KM, Jim HSL, Small BJ, Faul LA, Meade $\mathrm{CD}$, et al. Effects of self-directed stress management training and home-based exercise on quality of life in cancer patients receiving chemotherapy: a randomized controlled trial. Psycho-Oncol. 2013;22:1229-35.

18. Foster C, Fenlon D. Recovery and self-management support following primary cancer treatment. Br J Cancer. 2011;105:S21-8.

19. Donelly CM, Lowe-Strong A, Rankin JP, et al. A focus group study exploring gynaecological cancer survivors' experiences and perceptions of participating in a RCT testing the efficacy of a homebased physical activity intervention. Support Care Cancer. 2013;21: 1697-708.

20. Ross WL, Le A, Zheng DJ, et al. Physical activity barriers, preferences, and beliefs in childhood cancer patients. Support Care Cancer. 2018;26:2177-84.

21. Wong JN, McAuley E, Trinh L. Physical activity programming and counselling preferences among survivors: a systematic review. Int J Behav Nutr Phys. 2018;15:48.

22. Nekhlyudov, L., Duijts, S., Hudson, S.V. et al.Addressing the needs of cancer survivors during the COVID-19 pandemic. J Cancer Surviv 14, 601-606 (2020). https://doi.org/10.1007/s11764-02000884-w.

23. Richardson A, Addington-Hall J, Amir Z, Foster C, Stark D, Armes $\mathrm{J}$, et al. Knowledge, ignorance and priorities for research in key areas of cancer survivorship: findings from a scoping review. $\mathrm{Br} \mathbf{J}$ Cancer. 2011;105:S82-94.

24. Hathiramani S, Pettengell R, Moir H, Younis A. Relaxation and exercise in lymphoma survivors (REIL study): a randomised clinical trial protocol. BMC Sports Sci Med Rehabil. 2019;11:17.

25. Aaronson NK, Ahmedzai S, Bergman B, Bullinger M, Cull A, Duez NJ, et al. The European Organization for Research and Treatment of Cancer QLQ-C30: a quality-of-life instrument for use in international clinical trials in oncology. J Natl Cancer Inst. 1993;85(5):365-76.

26. Fayers P, Bottomley A, EORTC Quality of Life Group; Quality of Life Unit. Quality of life research within the EORTC-the EORTC QLQ-C30. European Organisation for Research and Treatment of Cancer. Eur J Cancer. 2002;38(Suppl 4):S125-33.

27. Oken MM, Creech RH, Tormey DC, Horton J, Davis TE, McFadden ET, et al. Toxicity and response criteria of the eastern cooperative oncology group. Am J Clin Oncol. 1982;5:649-55.

28. EORTC. The future of cancer therapy. The European Organisation for Research and Treatment of Cancer. 2018. https://www.eortc. org/app/uploads/2018/06/InformationBooklet A4 EORTC 1406-18 FINAL.pdf Accessed 11 Aug 2020.

29. Giesinger JM, Kieffer JM, Fayers PM, Groenvold M, Petersen MA, Scott NW, et al. Replication and validation of higher order models demonstrated that a summary score for the EORTC QLQ-C30 is robust. J Clin Epidemiol. 2016;69:79-88.

30. Osoba D, Rodrigues G, Myles J, Zee B, Pater J. Interpreting the significance of changes in health-related quality-of-life scores. J Clin Oncol. 1998;16(1):139-44.

31. Hui D, Glitza I, Chisholm G, Yennu S, Bruera E. Attrition rates, reasons, and predictive factors in supportive care and palliative oncology clinical trials. Cancer. 2013;119(5):1098-105.

32. Schulz KF, Altman DG, Moher D. CONSORT 2010 statement: updated guidelines for reporting parallel group randomised trials. BMJ. 2010;340:c332.

33. Courneya KS, Sellar CM, Stevinson C, McNeely ML, Peddle CJ, Friedenreich CM, et al. Randomized controlled trial of the effects of aerobic exercise on physical functioning and quality of life in lymphoma patients. J Clin Oncol. 2009;27(27):4605-12.

34. Kessels E, Husson O, van der Feltz-Cornelis CM. The effect of exercise on cancer-related fatigue in cancer survivors: a systematic review and meta-analysis. Neuropsychiatr Dis Treat. 2018;14:479 94.
35. Ferrer RA, Huedo-Medina TB, Johnson BT, Ryan S, Pescatello LS. Exercise interventions for cancer survivors: a meta-analysis of quality of life outcomes. Ann Behav Med. 2011;41(1):32-47.

36. Fong DYT, Ho JWC, Hui BPH, Lee AM, Macfarlane DJ, Leung SSK, et al. Physical activity for cancer survivors: meta-analysis of randomised controlled trials. BMJ. 2012;344:e70.

37. Macmillan Cancer Support. Physical activity and cancer. 2017. https://www.macmillan.org.uk/ images/the-importance-physicalactivity-for-people-living-with-and-beyond-cancer_tcm9-290123. pdf Accessed 11 August 2020.

38. Schmitz KH, Courneya KS, Matthews C, Demark-Wahnefried W, Galvão DA, Pinto BM, et al. American college of sports medicine roundtable on exercise guidelines for cancer survivors. Med Sci Sports Exerc. 2010;42:1409-26.

39. Rock CL, Doyle C, Demark-Wahnefried W, et al. Nutrition and physical activity guidelines for cancer survivors. CA Cancer J Clin. 2012;62:242-74.

40. Campbell A, Stevinson C, Crank H. The BASES expert statement on exercise and cancer survivorship. J Sports Sci. 2012;30:949-52.

41. Huang HP, He M, Wang HY, Zhou M. A meta-analysis of the benefits of mindfulness-based stress reduction (MBSR) on psychological function among breast cancer (BC) survivors. Breast Cancer. 2016;23(4):568-76.

42. Reich RR, Lengacher CA, Alinat CB, Kip KE, Paterson C, Ramesar S, et al. Mindfulness-based stress reduction in posttreatment breast cancer patients: immediate and sustained effects across multiple symptom clusters. J Pain Symptom Manag. 2017;53:85-95.

43. Greenlee H, DuPont-Reyes MJ, Balneaves LG, Carlson LE, Cohen MR, Deng G, et al. Clinical practice guidelines on the evidencebased use of integrative therapies during and following breast cancer treatment. CA Cancer J Clin. 2017;67:194-232.

44. Mao JJ, Palmer CS, Healy KE, Desai K, Amsterdam J. Complementary and alternative medicine use among cancer survivors: a population-based study. J Cancer Surviv. 2011;5:8-17.

45. Rausch Osian S, Leal AD, Allmer C, Maurer MJ, Nowakowski G, Inwards DJ, et al. Widespread use of complementary and alternative medicine among non-Hodgkin lymphoma survivors. Leuk Lymphoma. 2015;56(2):434-9.

46. Hamilton AS, Miller MF, Arora NK, Bellizzi KM, Rowland JH. Predictors of use of complementary and alternative medicine by non-Hodgkin lymphoma survivors and relationship to quality of life. Integr Cancer Ther. 2012;12(3):225-35.

47. Eyles C, Leydon GM, Hoffman CJ, Copson ER, Prescott P, Chorozoglou M, et al. Mindfulness for the self-management of fatigue, anxiety, and depression in women with metastatic breast cancer: a mixed methods feasibility study. Integr Cancer Ther. 2015;14(1):42-56.

48. Beatty L, Kemp E, Butow P, Girgis A, Schofield P, Turner J, et al. A systematic review of psychotherapeutic interventions for women with metastatic breast cancer: context matters. Psycho-Oncol. 2018;27:34-42.

49. Vissers PAJ, Thong MSY, Pouwer F, Zanders MMJ, Coebergh JWW, van de Poll-Franse LV. The impact of comorbidity on health-related quality of life among cancer survivors: analyses of data from the PROFILES registry. J Cancer Surviv. 2013;7:60213.

50. Willems RA, Bolman CAW, Mesters I, Kanera IM, Beaulen AAJM, Lechner L. Cancer survivors in the first year after treatment: the prevalence and correlates of unmet needs in different domains. Psycho-Oncol. 2016;25:51-7.

51. Schneerson C, Taskila T, Greenfield S, Gale N. A survey investigating the associations between self-management practices and quality of life in cancer survivors. Support Care Cancer. 2015;23: 2655-62. 
52. Kalter J, Buffart LM, Korstjens I, van Weert E, Brug J, Verdonckde Leeuw IM, et al. Moderators of the effects of group-based physical exercise on caner survivors' quality of life. Support Care Cancer. 2015;23:2623-31.

53. Korszum A, Sarker S, Chowdhury K, et al. Psychosocial factors associated with impact of cancer in longterm haematological cancer survivors. Br J Haematol. 2014;164:790-803.

54. Smith SK, Mayer DK, Zimmerman S, Williams CS, Benecha H, Ganz PA, et al. Quality of life among long-term survivors of nonHodgkin lymphoma: a follow-up study. J Clin Oncol. 2013;31(2): 272-9.

55. Lee YH, Lai GM, Lee DC, Tsai Lai LJ, Chang YP. Promoting physical and psychological rehabilitation activities and evaluating potential links among cancer-related fatigue, fear of recurrence, quality of life, and physiological indicators in Cancer survivors. Integr Cancer Ther. 2018;17(4):1183-94.

56. Scott DA, Mills M, Black A, et al. Multidimensional rehabilitation programmes for adult cancer survivors. Cochrane Database Syst Rev. 2013;2013(3):CD007730.

57. Hardcastle SJ, Glassey R, Salfinger S, Tan J, Cohen P. Factors influencing participation in health behaviours in endometrial cancer survivors. Psycho-Oncol. 2017;26(8):1099-104.

58. Vallerand JR, Rhodes RE, Walker GJ, Courneya KS. Feasibility and preliminary efficacy of an exercise telephone counselling intervention for hematologic cancer survivors: a phase II randomized controlled trial. J Cancer Surviv. 2018;12:357-70.

59. Mikolasek M, Witt CM, Barth J. Adherence to a mindfulness and relaxation self-care app for cancer patients: mixed-methods feasibility study. JMIR Mhealth Uhealth. 2018;6(12):e11271.
60. Post KE, Flanagan J. Web based survivorship interventions for women with breast cancer: an integrative review. Eur J Oncol Nurs. 2016;25:90-9.

61. NHS England. Clinical guide for the management of noncoronavirus patients requiring acute treatment: cancer. 2020. https://www.england.nhs.uk/coronavirus/wp-content/uploads/ sites $/ 52 / 2020 / 03 /$ specialty-guide-acute-treatment-cancer-23march-2020.pdf Accessed 8 Jun 2020.

62. Chartered Society of Physiotherapy. Face-to-face or not? 2020. https://www.csp.org.uk/system/files/publication_files/ F2FCountrydocMASTER.docx.pdf Accessed 8 Jun 2020.

63. Schmidt ME, Wiskemann J, Krakowski-Roosen H, Knicker AJ, Habermann N, Schneeweiss A, et al. Progressive resistance versus relaxation training for breast cancer patients during adjuvant chemotherapy: design and rationale of a randomized controlled trial (BEATE study). Contemp Clin Trials. 2013;34(1):117-25.

64. Vermaete N, Wolter P, Verhoef G, Gosselink R. Physical activity and physical fitness in lymphoma patients before, during, and after chemotherapy: a prospective longitudinal study. Ann Hematol. 2014;93(3):411-24.

65. Korkeila K, Suominen S, Ahvenainen J, Ojanlatva A, Rautava P, Helenius $\mathrm{H}$, et al. Non-response and related factors in a nation-wide health survey. Eur J Epidemiol. 2001;17(11):991-9.

Publisher's note Springer Nature remains neutral with regard to jurisdictional claims in published maps and institutional affiliations. 